\title{
A presença da festa de Sucot na literatura joanina e na liturgia cristã
}

\author{
The presence of the feast of Sucot in \\ johannine literature and the christian liturgy
}

Gilvan Leite de Araujo

\section{Resumo}

O cristianismo primitivo recebeu das suas raízes judaicas as Escrituras, costumes, tradições e uma sólida base cultual. As três grandes Festas Judaicas, que por sua natureza fazem memória do evento do Êxodo, deixam a sua marca na liturgia cristã. A Literatura Joanina, ao tratar destas Festas, faz menção explícita à Festa de Sucot. Habitualmente evidencia-se Pessach e Shavuot quando se trata das origens da liturgia cristã. Contudo, um olhar atento sobre a Festa de Sucot revela diversos traços pouco compreendidos da origem da liturgia cristã.

Palavras-chave: Liturgia Cristã; Festa de Sucot; Literatura Joanina.

\begin{abstract}
The ancient Christianity has received from its Jewish roots the Scriptures, customs, traditions and a solid base cultic. The three major Jewish Feasts which by their nature are memory of the Exodus leaves its mark in Christian liturgy. The Johannine Literature to treat these festivities makes explicit mention of Feast of Sukkot. Usually it is evident Pessach and Shavuot when it comes to the origins of the Christian liturgy. However, a close look at the Feast of Sukkot reveals various no understood traits of the origin of the Christian liturgy.
\end{abstract}

Keywords: Christian liturgy; Feast of Sukkot; Johannine Literature. 


\section{Introdução}

Os cristãos vindos do judaísmo com certeza conheceram e viveram aquilo que era próprio das suas raízes. Assumindo à novidade cristã, eles a absorvem e a interpretam a partir de suas tradições. O livro dos Atos dos Apóstolos narra que os primeiros cristãos "dia após dia, unânimes, mostravam-se assíduos no Templo..." (2,46; cf. At 24,17-18). Esta perícope é um exemplo de que os cristãos provenientes do judaísmo portavam consigo suas tradições, interpretando-as a partir de uma ótica diversa. A Torá continua sendo a base normativa, porém, agora, reinterpretada a partir do evento Jesus Cristo. Isto representava um desafio para o cristianismo nascente. O confronto entre Pedro e Paulo em Antioquia, sobre aquilo que é essencial ou relativo para o cristianismo, bem como sobre aquilo que possa ser superado ou incrementado na passagem do judaísmo para o cristianismo, ilustra bem a fase de transição do judaísmo para o cristianismo (cf. Gl 2).

Que os Apóstolos e os demais cristãos, de origem judaica, tenham procurado transpor e reler elementos culturais e religiosos do judaísmo para o cristianismo, é um fato. Contudo, o que foi levado em consideração ao aderir ou rejeitar certos elementos culturais e religiosos? Por exemplo, da Pessach judaica surgirá a Páscoa cristã, ou seja, é relida a partir da Paixão, Morte e Ressurreição de Jesus Cristo. Da Festa de Shavuot surgirá a festa cristã de Pentecostes, que passa a celebrar a vinda do Espírito Santo sobre os Apóstolos. Leva-se em conta que o Quarto Evangelho não faz absolutamente nenhuma menção a esta solenidade. Contudo, quando se indaga sobre a "maior e mais solene festa de Israel", como afirmava Flávio Josefo" ${ }^{1}$, ou seja, a Festa de Sucot em ambiente cristão, parece existir um vacuum. Diante disto, deve-se indagar até que ponto a Festa de Sucot tenha sido assimilada e, caso tenha sido assimilada, como se deu esta assimilação pelo cristianismo.

Refletindo sobre a influência da Festa de Sucot no cristianismo primitivo depara-se imediatamente com o Evangelho de João, que é o único texto neotestamentário a fazer menção explícita a esta solenidade (cf. Jo 7,2).

O texto atual do Evangelho de João é resultado de reelaborações sucessivas (Brown propõe pelo menos três fases) $)^{2}$. O substrato original do Quarto Evangelho manifesta, claramente, uma íntima relação com o Templo de Jeru-

\footnotetext{
${ }^{1}$ Rubenstein, J.L. The History of Sukkot in the Second Temple and Rabbinic Periods. Atlanta, Georgia: Scholars Press, 1995, p. 83.

${ }^{2}$ Brown R.E., Introduzione al Vangelo di Giovanni. Brescia: Queriniana 2007.
} 
salém. Um dos indícios desta íntima relação é justamente a Festa de Sucot. Esta solenidade serve como palco para as ações de Jesus neste Evangelho, pondo em evidência que o humus no qual surge a comunidade joanina é o ambiente do Templo de Jerusalém, possivelmente em torno da vida sacerdotal, diferente dos Evangelhos Sinóticos, que ambientam Jesus preferencialmente em torno da vida sinagogal.

\section{A Festa de Sucot}

A Festa de Sucot, dentro do universo gentílico, mesmo sendo a maior e mais solene festa de Israel, era concebida pelo paganismo como uma cópia da festa de Dionísio/Baco, pelas semelhanças existentes entre elas. Este poderia ter sido um dos motivos da não assimilação da Festa de Sucot dentro do cristianismo. A disputa presente entre Plutarco e Símaco sobre a Festa de Sucot em Quaestiones Convivales IV 6,2 $2^{3}$ deixa clara a compreensão pagã desta solenidade. Na disputa Símaco procura demonstrar que a festa judaica de Sucot nada mais era do que uma cópia da Festa de Dionísio/Baco, realizada em plena vindima, com a ereção de tendas, júbilo, procissão de ramos, toque de cítaras e "bacanais" (comum na festa de Baco, mas não na festa de Sucot). As possíveis semelhanças entre Sucot e Baco podem ter contribuído para a não releitura de Sucot pelo cristianismo, principalmente por causa da perspectiva universal do cristianismo, que exigia contato com o mundo gentílico.

Outro ponto importante e fundamental para a atenuação de Sucot pelo cristianismo é que a Festa de Sucot possuía um cunho nacionalista e estava estreitamente relacionada com o Templo de Jerusalém, ou seja, Sucot evidenciava a identidade nacionalista judaica, motivo pelo qual ganhará importância em época amoraica, além de ter os seus símbolos usados como meio de propaganda nacionalista anti-romana durante as insurreições fracassadas de 70 e 135 d.C.

Além do mais, a Festa de Sucot não tinha um substrato histórico preciso, ou seja, fazia memória do Exxodo (lembrava que durante quarenta anos o Povo Eleito havia caminhado pelo deserto sobre a proteção divina; cf. Lv 23). Ainda em nível histórico, era mais perceptível a sua relação com o Templo de Jerusalém (cf. 1Rs 8; Esd 3). Rubenstein afirma que a chave para compreender o papel da Festa de Sucot ao interno da Literatura Joanina é o Templo de Jerusalém. O Templo serve como o principal elo de ligação entre os motivos esca-

\footnotetext{
${ }^{3}$ Quaestiones Convivales IV 6,2 foi escrito por Plutarco ao início do II sec. d.C. Provavelmente entre os anos 100 a 110 d.C.
} 
tológicos, principalmente aquele de Zc 14, e a Festa de Sucot. ${ }^{4}$ Umoh nota que o estudo do Templo a partir do Evangelho de João pode ajudar a compreender melhor a teologia e a orientação política do evangelista e da sua comunidade 5 . Além do que, o profundo conhecimento do Templo de Jerusalém por parte do autor do Quarto Evangelho põe em discussão a historicidade e a datação da sua obra. ${ }^{6}$ Umoh salienta que, acima de tudo, é importante levar em consideração que existia uma cultura judaica como pano de fundo e, por outro, um ambiente cristão em desenvolvimento.

\section{Evangelho de João e Sucot}

No Prólogo do Evangelho $(1,14)$, João relaciona as expressões "o Verbo se fez carne" e "habitou entre nós", evocando intencionalmente a teologia da Tenda/Templo do AT. ${ }^{7}$ Jesus cumpre a função de Templo (cf. Jo 4,18; 7,37-38 e 19,34$)$ como lugar onde o céu a terra se encontram, cumprindo, assim, as promessas proféticas do Templo Futuro, de onde jorra a Água da Vida (cf. Ez 47; J1 4,18; Zc 13,1; 14,8). A alusão feita por Jesus a Natanael (cf. Jo 1,45-51), com respeito ao Sonho de Jacó (cf. Gn 28,10-17), evoca diretamente a fundação do santuário de Betel. ${ }^{8}$ No diálogo Jesus anuncia a Natanael que este verá o "céu aberto e os anjos de Deus subindo e descendo sobre o Filho do Homem" (Jo 1,51). No relato de Gn 28,10-22, Jacó, durante a sua viagem, decide passar a noite "em um certo lugar" e reclina a cabeça sobre uma pedra. Durante a noite vê, em sonho, uma escada que chega aos céus e nela anjos que sobem e descem. O Senhor, diante de Jacó, lhe diz ser o Deus de Abraão e de Isaac e que concede a Jacó aquela terra à sua descendência. No dia seguinte Jacó diz: "Este lugar é terrivel! Não é nada menos que uma casa de Deus a porta do céu!"' (Gn 28,17). Toma a pedra que lhe havia servido de travesseiro e a ergue como uma estela, derramando sobre ela óleo e denominando aquele lugar de "Betel". Na transposição do relato, Jesus se faz o "novo santuário de Betel". Provavelmente o autor do Quarto Evangelho conhecia a tradição judaica que interpretava a escada

\footnotetext{
${ }^{4}$ Cf. Rubenstein, J.L. The History of Sukkot..., p. 93-94.

${ }^{5}$ Uмон. C. The Temple in the Fourth Gospel. In: Labahn M. Schöltissek K. Strotmann A. (orgs). Israel und seine Heilstraditionen in Johannesevangelium. Paderbon: F. Schöning 2004, p. 314.

${ }^{6}$ Cf. Uмон. C. The Temple in the Fourth Gospel. p. 314.

${ }^{7}$ Cf. Spatafora, A. From the Temple of God to God as the Temple. Tesi Gregoriana 27. Roma: Editrice Pontifícia Università Gregoriana 1997, p. 115; Uмон. C. The Temple in the Fourth Gospel, p. 315.

${ }^{8}$ Cf. Spatafora, A. From the Temple of God to God as the Temple, p. 115.
} 
de Jacó como símbolo principalmente do Monte Sinai e do Templo. ${ }^{9}$ Como a escada de Betel era fixa na terra e chegava aos céus, assim, a base do Monte Sinai era firmemente estabelecida sobre a terra, enquanto chamas do seu cimo chegavam aos céus (cf. Dt 4,11). Os anjos que sobem e descem a escada são Moisés e Aarão, no ato de subir e descer o Sinai (Gen R 68,12 a 28,12;// Es R 42,2 a 32,7). ${ }^{10} \mathrm{~A}$ escada do Templo de Jerusalém que conduzia ao altar, também era representada através da imagem da escada de Jacó. A terra do terreno, sobre o qual era construído o Templo, era vista como a terra com a qual foi modelado o altar (cf. Ex 20,24). Os sacerdotes são os anjos, que subiam e desciam a escada do Templo. O Senhor, que estava sempre de pé diante de Jacó (cf. Gn 28,13), também "estava de pé junto ao altar" (Am 9,1). As palavras ditas por Jacó: "Este lugar é terrivel! Não é nada menos que uma casa de Deus e a porta do céu!' (Gn 28,17) se aplicavam muito bem ao Templo de Jerusalém. O Templo era também, a "Casa de Deus" e a "Porta do Céu"."1

O tema do Templo é retomado, indiretamente, no diálogo entre Jesus e a Mulher Samaritana. Esta afirma que "nossos pais adoraram nesta montanha, mas vós dizeis que é em Jerusalém que está o lugar onde é preciso adorar" (Jo $4,20)$, enquanto Jesus lhe responde: "nem nesta montanha nem em Jerusalém adorareis o Pai" (Jo 4,21). O diálogo se desenvolve a respeito do legítimo lugar aonde se deve adorar. Anteriormente, Jesus já havia oferecido a Água da Vida, dada por ele mesmo à Samaritana, sendo que esta estabelece uma relação entre Jesus e Jacó. A perícope de Jo 4,1-42 termina com a profissão de fé dos samaritanos: "nós próprios ouvimos, e sabemos que esse [Jesus] é verdadeiramente o salvador do mundo" (Jo 4,42).

Em Jo 7-8 a transposição entre Jesus e Templo é evidente. Jesus no templo evoca o tema da Água da Vida e da Luz do Mundo, em relação direta com os ritos da Festa de Sucot, da qual Ele está participando. O relato de Jo 7,1-8,59 está inserido no último ano da vida de Jesus, sendo que, após a subida para Jerusalém, Ele não mais retornará para a Galiléia. $\mathrm{O}$ autor procura atribuir as prerrogativas do Templo de Jerusalém e da Festa de Sucot a Jesus. Evidencia-se claramente que Jesus é o "novo" Templo que oferece o Espírito Santo ao mundo. Aqui Jesus se faz o Templo dos tempos escatológicos, dentro da solenidade dos tempos escatológicos, que, segundo a tradição de Zc 14, não era outra que a Festa de Sucot.

\footnotetext{
9 Binni, W. \& Boschi, B.G. Cristologia Primitiva, Dalla teofania del Sinài all'Io Sono giovanneo. Bologna: EDB 2004, p. 223.

${ }^{10}$ Binni, W. \& Boschi, B.G. Cristologia Primitiva, p. 223.

${ }^{11}$ Binni, W. \& Boschi, B.G. Cristologia Primitiva, p. 223.
} 
Em toda a primeira parte do Evangelho de João, no chamado "Livro dos Sinais", Jesus é apresentado pelo Evangelista João como o Templo dos Tempos Escatológicos. Nele Deus habita com a humanidade. Na sua humanidade, Jesus santifica todo o universo e o Espírito Santo é enviado para cumprir esta missão de santificação. ${ }^{12}$

\section{Apocalipse e Sucot}

O Apocalipse de João tem uma maior proximidade com o AT, no que diz respeito ao Templo de Jerusalém, do que os demais textos apocalípticos. ${ }^{13} \mathrm{O}$ AT nos apresenta duas perspectivas em relação ao Templo de Jerusalém; na primeira, presente no Pentateuco e nos Livros Históricos, encontramos um amplo material sobre a vida cultual do Templo e sua importância dentro da comunidade dos Filhos de Israel. O segundo, parte da perspectiva pós-exílica, que preanuncia um templo escatológico, como aquele da profecia de Ez 40-48. ${ }^{14}$

No Apocalipse de João temos uma progressiva evolução sobre o conceito de Templo. Em Ap 3,12, Jesus falando a comunidade de Filadélfia, promete ao "vencedor" ser "uma coluna do Templo do meu Deus" (Ap 3,12), e terá escrito sobre si, por Jesus Cristo, “...Cidade do meu Deus..." (Ap 3,12). Os "trajados de branco", vindos da grande tribulação, servem a Deus dia e noite no seu Templo (cf. Ap 7). Aqui, conforme vimos acima, a perícope evoca a Festa de Sucot. No relato, um dos anciãos anuncia ao vidente que Deus estenderá a sua tenda; com isso o autor do Apocalipse estabelece uma relação entre Templo e Tenda e evoca as tradições do deserto e aquelas ligadas ao Templo de Jerusalém, ${ }^{15}$ sendo que o pano de fundo de Ap 7 é, por excelência, a profecia de Zc 14.

Ap 11, também, aborda o tema do "Templo de Deus" (11,1.2.19). O autor fala de templo terrestre e templo celeste respectivamente. Na primeira parte, o vidente é convidado, pela "voz do céu" $(10,8)$, a medir o Templo de Deus, na "cidade santa". Na segunda parte, o Templo de Deus se encontra no céu. Este abre as portas e apresenta a "Arca da Aliança" (cf. 11,19). O tema do Templo Celeste evoca, no Antigo Testamento, a crise pós-exílica sobre o conceito de templo e realeza eterna anterior ao exílio. A crise também se situava sobre os conceitos de legitimidade sacerdotal e pureza de Israel. O profetismo exílico

\footnotetext{
${ }^{12}$ Cf. Spatafora, A. From the Temple of God to God as the Temple, p. 116.

${ }^{13}$ Cf. Spatafora, A. From the Temple of God to God as the Temple, p. 296.

${ }^{14}$ Cf. Spatafora, A. From the Temple of God to God as the Temple, p. 296.

${ }^{15}$ Cf. Rubenstein, J.L. The History of Sukkot..., p. 92-93.
} 
e pós-exílico anuncia um templo perfeito e eterno no céu, reservado para os tempos escatológicos. O Apocalipse de João retoma este tema, provavelmente diante da crise gerada após a Guerra Judaica de 70 d.C., na qual o Templo de Jerusalém será destruído pelo exército romano.

Ap 14 não deixa claro se o templo em questão é celeste ou terrestre. Levando-se em consideração que dele saem anjos, podemos conjecturar que se trate de um templo celeste. Contudo, em Ap 15 o autor trata explicitamente de templo celeste, tendo as diversas tradições antigo-testamentárias, a respeito do Templo/Tenda, entrelaçadas. Ap 15,5 apresenta "o templo da tenda do Testemunho que está no céu" de onde saem anjos. O fato de sair anjos pode nos indicar que a visão de Ap 14 trata-se na realidade de um Templo Celeste. A visão é abrangente, pois o autor aproxima a tradição da Tenda do Deserto, do Santuário de Betel e do Templo de Jerusalém. Durante a visão o tema da Presença Divina (Shekinah) é evidenciado através do vidente anunciando que "o templo se encheu de fumaça por causa da Glória de Deus e do seu poder, de modo que ninguém podia entrar no templo..." $(15,8)$. A imagem resgata 1 Rs 8,10 -11 e Is 6,4 respectivamente.

Em Ap 16 aparece apenas "uma voz forte que vinha do Templo" (cf. 16,1.17), que sem dúvida trata-se da voz de Deus; leve-se em conta que o autor do Apocalipse faz usa de imagens, a fim de salvaguardar a transcendência divina segundo o modelo antigo-testamentário.

Finalmente, em Ap 21,22 descreve-se a Nova Jerusalém, sem a presença de um Templo, "pois o seu Templo é o Senhor, o Deus Todo-poderoso, e o Cordeiro".

O Templo físico desaparece completamente da ótica do Apocalipse de São João e todos os atributos referentes ao Templo terrestre são aplicados e levados a perfeição em Deus Pai e Filho que se torna o Templo Escatológico. Assim quando Jesus fala a Nicodemos, no Quarto Evangelho, que os verdadeiros adoradores adorarão em espírito e verdade, Ele evidência o Culto Perfeito no Templo Perfeito. ${ }^{16}$

\section{Sucot e Domingo de Ramos = Rito do Lulav}

Daniélou afirma que a "Entrada Triunfal de Jesus em Jerusalém" (=Domingo de Ramos) surge como a realização da verdadeira Festa de Sucot do fim dos tempos. ${ }^{17}$ A mesma imagem festiva da exaltação do Senhor através

${ }^{16}$ Cf. Spatafora, A. From the Temple of God to God as the Temple, p. 296.

${ }^{17}$ DanièLou, J. Lês Quatre-Temps de Septembre et la Fête des Tabernacles. La Maison-Dieu 46 
da multidão com palmas nas mãos, a nível escatológico, é apresentada por Ap 7. Contudo, os Evangelhos ligam a Entrada Triunfal de Jesus em Jerusalém com a Festa da Páscoa. Os Evangelhos Sinóticos narram que a multidão estende as suas vestes sobre o caminho no qual passava Jesus (cf. Mt 21,1-9; Mc 11,1-10 e Lc 19,28-38). O Quarto Evangelho (cf. Jo 12,12-19) explicita categoricamente que a multidão toma "ramos de palmeira" (=lulav) e vai ao encontro de Jesus cantando o S1 118,25, que fazia parte do Hallel. Nota-se que aqui a multidão não estende roupas ou ramos por onde passa Jesus, mas toma os ramos e vai ao encontro de Jesus aclamando (cf. Jo 12,13), ou seja, a iniciativa em João não é de Jesus, mas do povo que subira para Jerusalém para celebrar Pessach ou Sucot? Todas estas particularidades, obrigatoriamente, relacionam o relato de João com a Festa de Sucot. Tendo em vista que não existiam ramos de palmeiras em Jerusalém e elas eram utilizadas apenas na solenidade de Sucot e todas as características apontadas fazem parte da liturgia de $\operatorname{Sucot}^{18}$, apesar do relato estar inserido na solenidade de Pessach (cf. Jo 12,1).

Poder-se-ia dizer que Jo 12,12-19 foi deslocado do relato original, adequando-se com o relato da Páscoa. É bem provável, levando-se em conta o conflito entre os cap. 11 e $12 .{ }^{19}$ Em todo caso, o relato da entrada triunfal de Jesus em Jerusalém baseia-se Zc 9,9 (cf. Zc 9-10 e 14), que possui como pano de fundo a Festa de Sucot.

\section{Sucot e a Epifania do Senhor}

A origem da Festa da Epifania é controversa. Merras ${ }^{20}$ apresenta uma síntese do panorama atual em torno da origem da Festa da Epifania. ${ }^{21}$ Recentemente Thankachan ${ }^{22} \mathrm{e}$ Thadathil ${ }^{23}$ se dedicaram à pesquisa do tema da Epifania,

\footnotetext{
(1956), p. 118.

${ }^{18}$ Rubenstein, J.L. The History of Sukkot..., p. 86-87.

${ }^{19}$ Jo 11,2 narra que "María era aquela que ungira o Senhor com bálsamo e lhe enxugara os pés com os cabelos". Tal fato acontecerá somente no capítulo seguinte, ou seja, Jo 12,3. O relato de Jo 12,12 narra que a multidão tinha vindo para a "festa". Por outro lado o cap. 12 apresenta problema geográfico entre Betânia e Jerusalém.

${ }^{20}$ Merras, M. The Origins of the Celebration of the Christian Feast of Epiphany, an ideological, cultural and historical study, Joensuu Filand: Joensuu University Press, 1995.

${ }^{21}$ Merras, M. The Origins of the Celebration of the Christian Feast of Epiphany, p. 2-6.

${ }^{22}$ Thankachan, T. The Feast of the Epiphany in the Church of the East (Assyrian, Chaldean and Syro-Malabar). Romae: Pontificio Istituto Orientale, 2004.

${ }^{23}$ ThadathiL, K. The Feast of the Epiphany in the Malankara and the West Syrian Traditions.
} 
em nível de Doutorado, através do Pontifício Instituto Oriental. Contudo, as duas pesquisas se concentram no ambiente da Igreja Síria do III-IV sec. d.C.

A Festa de Sucot, com toda probabilidade, continuou a ser celebrada em ambiente judeu-cristão. ${ }^{24}$ Dentro do ambiente cristão, a Festa de Sucot passa a celebrar a Manifestação Messiânica de Jesus (Jesus Cristo, Rei do Universo, Batismo do Senhor, Transfiguração do Senhor, Epifania...), que Comblin identifica com os temas da Nova Jerusalém, da Transfiguração do Senhor, Jesus no Templo em Jo 7-8, Batismo do Senhor e com os símbolos funerários cristãos (júbilo, luz, palmas, coroa). ${ }^{25}$ Porém, segundo Comblin, a Festa de Sucot Cristã não sobreviveu por muito tempo, provavelmente em razão da sua temática tradicional, profundamente ligada ao messianismo temporal dos judeus e pela predominância da Festa das Páscoa sobre a liturgia cristã. Os motivos alegados por Comblin são: o messianismo temporal judaico e a adoção do calendário grego, com a passagem do ano-novo de setembro para janeiro, fazendo com que a Festa de Sucot cristã perdesse a sua fundamentação cronológica. Com a mudança de data (de setembro a janeiro) o cristianismo oriental dá origem à Festa da Epifania. ${ }^{26}$

Merras questiona: quais são as provas de uma possível continuação da Festa de Sucot no cristianismo? A autora responde dizendo que o Evangelho e o Apocalipse de São João fazem menção direta e indireta à Festa de Sucot e isto, com toda certeza, manifesta a importância desta Festa para cristianismo proveniente do judaísmo. ${ }^{27}$

A Festa da Epifania apresenta todas as características de uma Festa de Sucot Cristã: manifestação messiânica de Jesus, festa da água e da luz e, enfim, a Festa do Batismo de Jesus. ${ }^{28}$ A Festa da Epifania foi, posteriormente, ampliada com o tema do nascimento de Jesus e a adoração dos Magos vindos do Oriente. Contudo, os temas do batismo e da manifestação de Jesus estão na origem da Festa da Epifania e sempre em íntima relação com a tradição da festa judaica de Sucot. ${ }^{29}$

\footnotetext{
Romae: Pontificio Istituto Oriental, 2001.

${ }^{24}$ Merras, M. The Origins of the Celebration of the Christian Feast of Epiphany, p. 18.

${ }^{25}$ Comblin, J. La Fête des Tabernacles. In: Assemblées du Seigner 72 (1964) p. 60-65.

${ }^{26}$ Comblin, J. La Fête des Tabernacles, p. 65.

${ }^{27}$ Merras, M. The Origins of the Celebration of the Christian Feast of Epiphany, p. 55.

${ }^{28}$ Comblin, J. La Fête des Tabernacles, p. 65-66.

${ }^{29}$ Cf. Comblin, J. La Fête des Tabernacles, p. 66.
} 
Quanto a questão da data da Festa da Epifania, ou seja, 06 de janeiro, Merras confirma a teoria de Talley, segundo o qual é uma questão aberta e que a Festa da Epifania não provém da assimilação da Festa da Água do Nilo celebrada neste dia. ${ }^{30}$ Merras apresenta Clemente de Alexandria (+ou- 215 d.C.) como uma das antigas fontes sobre o tema da Festa da Epifania. ${ }^{31}$ Clemente de Alexandria comenta sobre os seguidores de Basilides que celebravam o Batismo de Jesus no dia 06 ou 10 de janeiro. Por outro lado, Epifânio fala de uma festa conhecida como Solenidade de Aion, celebrada pelos gnósticos entre $5 / 6$ de janeiro. O motivo pelo qual os gnósticos celebravam a Solenidade de Aion entre 5/6 de janeiro é incerto. Contudo, com certeza, segundo Merras, não existe relação entre a Solenidade de Aion e Festa Cristã da Epifania. ${ }^{32}$

As poucas fontes existentes sobre a origem da Festa da Epifania nos remetem para o Egito e posteriormente para a Síria. Quanto à Igreja do Egito, Eusébio afirma São Marcos como fundador do cristianismo egípcio. Contudo, atualmente alguns estudiosos apontam uma presença cristã no Egito anterior a São Marcos. ${ }^{33}$ Os Atos dos Apóstolos menciona Apolo ${ }^{34}$ como sendo de Alexandria do Egito "um judeu... natural de Alexandria..." (cf. At 18,24). Os judeus no Egito somavam em torno a $10 / 15 \%$ da população, sendo a presença

\footnotetext{
${ }^{30}$ Merras, M. The Origins of the Celebration of the Christian Feast of Epiphany, 4.10.

${ }^{31}$ Merras, M. The Origins of the Celebration of the Christian Feast of Epiphany, p. 12.

${ }^{32}$ Merras, M. The Origins of the Celebration of the Christian Feast of Epiphany, p. 12.

${ }^{33}$ Merras, M. The Origins of the Celebration of the Christian Feast of Epiphany, p. 65.
}

${ }^{34}$ A figura de Apolo é emblemática na relação entre Alexandria e Éfeso. O Atos dos Apóstolos apresenta Apolo como sendo um judeu $(18,24)$ originário de Alexandria $(18,24)$, que fora instruído no Caminho do Senhor $(18,25)$ e no fervor do espírito $(18,25)$, homem eloquente e versado nas Escrituras $(18,24)$ e que falava e ensinava com exatidão o que se refere a Jesus $(18,25)$. Contudo, conhecia apenas o batismo de João $(18,25)$. As informações fornecidas pelo texto do Atos dos Apóstolos são significativas, principalmente em relação à comunidade de origem de Alexandria, ou seja, Apolo ensina com exatidão sobre Jesus, mas conhece apenas o batismo de João. Por outro lado, o Atos dos Apóstolos nos informa que Apolo era um excelente pregador e que Priscila e Aquila tomam Apolo consigo e lhe expõe com mais exatidão o Caminho (cf. 18,26). Sendo Apolo um exímio conhecedor de Jesus, qual era a necessidade de Priscila e Aquila aprofundarem os seus conhecimentos? Possivelmente possa tratar-se de questões de ordem doutrinal. Levando-se em conta, hipoteticamente, uma possível presença da literatura joanina (em fase embrionária?) em Alexandria, pode-se supor que tenha existido conflito de ordem doutrinal, ou seja, teologia paulina x teologia joanina? Além do mais, pode-se supor ainda que a literatura joanina tenha chegado a Éfeso através de Apolo? Em todo caso, um estudo sobre a figura de Apolo poderia fornecer dados interessantes, principalmente naquilo que diz respeito a possível presença da literatura joanina a Éfeso e Alexandria. Claro, lamentavelmente não sabemos exatamente qual era a doutrina pregada por Apolo e, por outro lado, temos a tradição de São Marcos no Egito, permanecendo toda a questão no nível de conjecturas. 
em Alexandria verdadeiramente numerosa. Por outro lado, não se pode dizer que o judaísmo no Egito era homogêneo e uniforme. ${ }^{35} \mathrm{O}$ ambiente intelectual de Alexandria não só permitiu a difusão do cristianismo no Egito, como motivou o aprofundamento teológico, com consequentes crises e avanços, ${ }^{36}$ como se pode perceber através das disputas cristológicas do III sec. d.C., no qual a Festa da Epifania, nas obras de Clemente e Orígines, vem atenuada em sua importância ao se mencionar apenas Páscoa e Pentecostes como festas cristãs, ${ }^{37}$ para reaparecer com todo o seu vigor no IV sec., com Atanásio e João Cassiano, considerando-a como a terceira festa cristã, na qual se celebra o batismo e a manifestação de Nosso Senhor como Deus. ${ }^{38}$

Na Síria, segundo Merras, a origem do cristianismo em Nisibis e Edessa é uma questão aberta. ${ }^{39}$ Os Ensinamentos de Addai, transmitido por Eusébio e manuscritos do V sec. d.C., são as únicas fontes sobre a origem do cristianismo na Síria. ${ }^{40}$ Segundo os Hinos de Efrém, existia o costume do batismo na noite da Festa de Epifania em 6 de janeiro. ${ }^{41}$

A Festa de Sucot forneceu a base na qual se desenvolveu a Festa Cristã da Epifania. As tradições da Festa da Epifania foram preservadas principalmente no Egito, apesar do problema de calendário apresentado por Atanásio, que possivelmente esteja em relação com a tradição da Festa de Sucot em relação ao fim das colheitas. ${ }^{42}$

Teologicamente, a Festa da Epifania nasce ligada à ideia de redenção. $\mathrm{O}$ nascimento carnal de Cristo e o seu batismo ${ }^{43}$, como protótipo de batismo para todos os cristãos, estão estreitamente conectados, e ambos são concebidos como necessários para atingir o "Paraíso Perdido". Na mente dos primeiros cristãos, segundo Merras, as promessas do AT se concretizavam: a Glória de Deus - seu Filho - desce sobre a terra possibilitando, como consequência, o retorno à beatitude anterior por meio do batismo. Estas duas noções formariam

\footnotetext{
${ }^{35}$ Merras, M. The Origins of the Celebration of the Christian Feast of Epiphany, p. 66.

${ }^{36} \mathrm{Cf}$. Merras, M. The Origins of the Celebration of the Christian Feast of Epiphany, p. 79-80.

${ }^{37}$ Merras, M. The Origins of the Celebration of the Christian Feast of Epiphany, p. 120.

${ }^{38}$ Merras, M. The Origins of the Celebration of the Christian Feast of Epiphany, p. 121.

${ }^{39}$ Merras, M. The Origins of the Celebration of the Christian Feast of Epiphany, p. 72.

${ }^{40}$ Merras, M. The Origins of the Celebration of the Christian Feast of Epiphany, p. 72.

${ }^{41}$ Cf. Merras, M. The Origins of the Celebration of the Christian Feast of Epiphany, p. 189.

${ }^{42}$ Merras, M. The Origins of the Celebration of the Christian Feast of Epiphany, p. 191.

${ }^{43}$ SELwyn. E.C. The Feast of Tabernacles, Epiphany, and Baptism. In: The Journal of Theological Studies 13 (1912), p. 225.
} 
o núcleo básico da primitiva Festa da Epifania. ${ }^{44}$ Daniélou difere da concepção de Merras, quanto ao tema da encarnação do Senhor, que é visto por ele como uma glosa posterior. Em todo caso, a Festa da Epifania está em relação com a manifestação de Jesus ao mundo, seja como uma criança que nasce, tradição posterior, ou como o Senhor que se manifesta ao mundo, tradição anterior.

\section{Conclusão}

Após a construção do Templo de Jerusalém, Salomão resgata as antigas tradições cultuais israelitas transladando a Arca da Aliança e Tenda para o Templo de Jerusalém. Deste modo se concentra em Jerusalém a tradição do deserto e aquela de Betel, tudo confirmado com a Presença da Nuvem que invade o Templo durante a sua consagração. Tudo isto ocorre em meio aos festejos da Festa de Sucot. A partir disto, se estabelece uma estreita relação entre a Festa de Sucot e o Templo de Jerusalém, passando esta a ser a solenidade do Templo (cf. 1Rs 8).

A estreita relação entre Templo e Festa de Sucot se fará sentir ao retorno do Exílio da Babilônia, quando os repatriados consagram o altar do Templo durante esta solenidade (Esd 3) e proclamam a lei (Ne 8), segundo a prescrição de Dt 31. Enquanto Zc 14 anuncia a era escatológica e a Jerusalém futura dentro do estreito vínculo com a Festa de Sucot, a Literatura Joanina entra dentro desta perspectiva escatológica e leva às últimas consequências.

A Literatura Joanina, na sua ênfase sobre o Templo, evidencia a Festa de Sucot e deixa um silêncio quanto à Festa de Pentecostes (Shavuot). As demais festas judaicas são evidenciadas, mas a importância aqui está no fato de que a Festa de Sucot desaparece totalmente do horizonte dos demais escritos neo-testamentários, ${ }^{45}$ enquanto conserva uma discreta presença dentro da literatura joanina. Diga-se discreta porque ela não é exaltada por si mesma, mas enquanto relacionada com o Templo de Jerusalém e na sua perspectiva do Templo Escatológico.

Na teologia do Quarto Evangelho, o Templo de Jerusalém é identificado

\footnotetext{
${ }^{44}$ Merras, M. The Origins of the Celebration of the Christian Feast of Epiphany, p. 192.

${ }^{45}$ Alguns estudiosos tendem a ver a Transfiguração do Senhor (Mt 17,3-8; Mc 9,2-8; Lc 9,2836) em termos de uma Festa de Sukkot dos tempos escatológicos. Os indícios são fortes, sendo ainda matéria de pesquisa. A Entrada Triunfal de Jesus em Jerusalém deixa transparecer claramente a Procissão de Ramos durante a Festa de Sukkot (cf. Mt 21,1-11; Mc 11,1-11; Lc 19,28-38 e Jo 12,12-16).
} 
por Jesus como "casa do meu Pai" (Jo 2,16) e imediatamente Jesus afirma que o Templo é o seu próprio corpo "santuário de seu corpo" $(2,16)$. Já no prólogo do Quarto Evangelho o lógos=Verbo (Jo 1,1) "se fez carne e veio habitar entre nós e nós vimos a sua Glória" $(1,14)$, ou seja, Deus vem morar no meio do seu povo através do seu Filho Único. Assim, o novo Templo é o próprio Filho Unigênito, no qual nós vemos a Glória de Deus (Shekinah). ${ }^{46}$ A transposição do templo físico de pedra, ou seja, o Templo de Jerusalém, para o templo de carne ganha uma nova dimensão no Apocalipse de São João, no qual o autor afirma que na Nova Jerusalém não existe mais templo, porque o templo é “ $o$ Senhor, o Deus Todo-poderoso, e o Cordeiro", e a sua Glória ilumina a cidade e o universo, pois não existe mais a necessidade nem da luz e nem do sol. Isto mostra que o Templo de Jerusalém teve uma forte influência dentro do ambiente joanino e no ministério de Jesus. ${ }^{47}$

O Templo de Jerusalém ${ }^{48}$ era sem dúvida a morada de Deus, repleto da "Nuvem", através da qual a "Glória do Senhor enchia o Templo" (cf. 1Rs $8,13)$. Isto quer dizer que a transcendência divina, Shekinah, que "os céus dos céus não podem conter" (cf. 1Rs 8,27) e muito menos o Templo construído por Salomão (cf. 1Rs 8,27), se abaixa ao nível terrestre e entra em contato com a fragilidade humana. ${ }^{49}$

Rubenstein evidencia que Sucot era o "paramount temples festival", assim, o culto do templo escatológico não pode ser outro, do que aquele de Sucot. ${ }^{50}$ Este, de fato, é o motivo pelo qual o profeta Zacarias ao descrever o culto do Templo escatológico, instintivamente o descreveu a partir de Sucot. ${ }^{51}$

Danièlou, por sua vez, acredita que a Festa de Sucot chegou a ser celebrada pelos judeus-cristãos à maneira de festa judia, durante o mês de setembro, dentro dos círculos cristãos da Ásia Menor, de onde, teria nascido a literatura joanina. ${ }^{52}$ Mas, como verificamos acima, a teologia joanina conflita com aquela paulina,

\footnotetext{
${ }^{46}$ Cf. Umoн, C. The Temple in the Fourth Gospel, p. 316-317.

${ }^{47} \mathrm{Cf}$. Uмон, C. The Temple in the Fourth Gospel, p. 316.

${ }^{48} \mathrm{Cf}$. STAger, L.E. Jerusalem and the Garden of Eden, p. 183. O Templo de Jerusalém era um microcosmo. Cópia e possuidora das prerrogativas das realidades terrestres e celestes criadas por Deus. Este microcosmo era apoiado sobre Sião, a montanha sagrada, que era a "Axis Mundi" ligando o céu a terra (cf. Sl 48,3; 76,3; 78,68-69; 132,13; 134,3).

${ }^{49}$ Cf. Lenhardt, P. La Tradition d'Israël sur la Présence Divine (Shekinah) - dans le Temple dans le monde éclaire la foi chrétienne en l'Incarnation. In Cahiers Ratisbone 2 (1997), p. 142.

${ }^{50}$ Rubenstein, J.L. The History of Sukkot..., p. 93.

${ }^{51}$ Cf. Rubenstein, J.L. The History of sukkot..., p. 93.

${ }^{52}$ Cf. Daniélou, J. Théologie du judéo-christianisme, Tournai, Paris 1958, p. 401.
} 
o que impede pensar uma comunidade joanina em Ásia Menor, pelos menos num primeiro estágio da formação da comunidade. Por outro lado, a escatologia joanina se inspira diretamente e, em primeiro lugar, na Festa de Sucot e nas esperanças escatológicas a esta associada, no judaísmo contemporâneo ao nascimento da literatura joanina. ${ }^{53}$ Deste modo, seguindo a tradição profética de Zc 9 e 14, a Festa de Sucot é o momento propício, segundo a perspectiva do Quarto Evangelho, para a manifestação messiânica de Jesus.

O percurso através da Festa de Sucot fornece fortes indícios de que esta tenha influenciado em modo significativo a liturgia cristã, ou seja, que tenha deixado suas marcas fortemente impressas. Claramente não se pode falar de uma Festa de Sucot Cristã, mas pode-se conceber uma Cristã Festa de Sucot.

A Festa de Sucot deixa traços indeléveis dentro da liturgia cristã. Não se pode dizer que ela tenha apenas desaparecido ou que não tenha entrado a fazer parte, como a maioria dos autores afirmam. ${ }^{54} \mathrm{Na}$ realidade, tem-se uma transposição festiva do judaísmo para o cristianismo. A dificuldade é que as duas primeiras principais festas judaicas, Páscoa e Pentecostes, passam para o cristianismo, com o mesmo nome de sua origem judaica. Enquanto a Festa de Sucot deixa seus traços indeléveis, mas não o nome. Sucot é um complexo litúrgico, com diversos ritos que se estendem por oito dias. Este complexo, como um todo, não entra a fazer parte do cristianismo, somente os seus ritos e sua teologia, distribuídos dentro do quadro litúrgico cristão, como a Entrada Triunfal de Jesus em Jerusalém (Domingo de Ramos), a Festa do Batismo do Senhor, a Festa da Epifania do Senhor, a Festa da Exaltação da Santa Cruz, a Transfiguração do Senhor, que entra em relação com a Festa da Epifania, com

\footnotetext{
${ }^{53}$ Comblin, J. La fête des Tabernacles, p. 61.

${ }^{54}$ Vicent afirma que: L'assenza della Festa di Sukkot nel calendario cristiano si deve as una convergenza di motivi. Innanzitutto, il significato complessivo di questa festa, come di tutte le altre, è stato assorbito dalla Pasqua personale di Gesù di Nazaret,... I pochi riferimenti alla festa $(\mathrm{Gv} 7,12 ; \mathrm{Ap} 7)$ in fondo sono un'interpretazione dell'esodo attraverso la figura di Gesù, in cui si condensano aspetti dell'AT. Si ricorre a Sukkot perché apporta un'interessante costellazione di temi dell'esodo (acqua, popolo in cammino, Dio che guida e protegge) e, sopratutto, una prospettiva universale e religiosa in alcuni testi profetici (Zc 14,16-19; LXX Am 9,11s). Esaminando i riferimenti alla festa nel NT, si comprende che la comunità cristiana non abbia utilizzato una presentazione escatologica e universalista di Sukkot come quella di Zc 14,16-19. VICENT, R. La Festa Ebraica delle Capanne (Sukkot), p. 235. A afirmação de Vicent é altamente redutiva e desconsidera toda a evolução da Festa de Sucot e, principalmente, não leva em consideração a perspectiva teológica de João. Afirmar que Sucot é apenas uma Festa da memória do Êxodo e que esta contém todos os elementos deste evento é desconsiderar as demais festas judaicas e toda uma longa tradição cultual e literária de Israel.
} 
a Solenidade de Jesus Cristo Rei do Universo, com o tema do Ano Litúrgico. Tryon-Montalembert, é mais audacioso ao afirmar que, se Sucot não chegou a constituir uma específica solenidade cristã, é porque toda a liturgia cristã possui a marca desta Festa. ${ }^{55}$ Claro que tal hipótese pode ser exagerada, mas, que Sucot deixou os seus traços na liturgia cristã, isto é inegável.

\section{Referências bibliográficas}

Bınni, W., \& Boschi, B.G. Cristologia Primitiva, Dalla teofania del Sinài all'Io Sono giovanneo. Bologna: EDB, 2004.

Brown, R.E. Introduzione al Vangelo di Giovanni. Brescia: Queriniana 2007.

Comblin, J. La fête des Tabernacles. Assemblées du Seigneur 72 (1964), pp.53-67.

DaniÉLou, J. Lês Quatre-Temps de Septembre et la Fête des Tabernacles. La Maison-Dieu 46 (1956), p. 114-136.

DaniéLou, J. Théologie du Judéo-christianisme. Paris-Tornai: Desclée de Brouwer, 1958.

Lenhardt, P. La Tradition d'Israël sur la Présence Divine (Shekinah) - dans le Temple dans le monde éclaire la foi chrétienne en l'Incarnation. Cahiers Ratisbone 2 (1997), p. 137-162.

Merras, M. The Origins of the Celebration of the Christian Feast of Epiphany, an ideological, cultural and historical study. Joensuu Finland: Joensuu Univerty Press, 1995.

Rubenstein, J.L. The History of Sukkot in the Second Temple and Rabbinic Periods. Atlanta, Georgia: Scholars Press, 1995.

Selwyn, E.C. The Feast of Tabernacles, Epiphany, and Baptism. The Journal of Theological Studies 13 (1912), p. 225-249.

Spatafora, A. From the 'Temple of God'to God as the Temple, Tesi Gregoriana 27. Roma: Editrice Pontificia Università Gregoriana 1997.

Stager, L.E., Jerusalem and the Garden of Eden. Eretz Israel 26 (1999), p. 183-194.

55 De Tryon-Montalembert, R. Les fêtes d'automne et la liturgie Chrétienne. In: Rencontre Chrétiens et Juifs 62 (1979) p. 205-213. 
ThadathiL, K. The Feast of the Epiphany in the Malankara and the West Syrian Traditions. Romae: Pontificium Institutum Orientale, 2001.

Thankachan, T. The Feast of the Epiphany in the Church of the East (Assyrian, chaldean and Syro-Malabar). Romae: Pontificium Institutum Orientale, 2004.

Tryon-Montalembert, R. De. Les Fêtes d'Automne et la Liturgia Chrétienne. Rencontre Chrétiens et Juifs 62 (1979), p. 205-213.

Umon, C. The Temple in the Fourth Gospel. In: Labahn, M. Scholtissek, K., Strotmann, A. (Orgs.). Israel und seine Heilstraditionen in Johannesevangelium. Paderbon: F. Schöningh 2004.

Vicent, R. La Festa Ebraica delle Capanne (Sukkot). Città del Vaticano: Libreria Editrice Vaticana 2000.

Gilvan Leite de Araujo Doutor em Teologia Bíblica pela Pontifícia Universidade São Tomás de Aquino - Angelicum de Roma Membro do Programa de Estudos Pós-Graduados da PUC-SP

São Paulo/SP - Brasil E-mail: glaraujo@pucsp.br

Recebido em: 01/06/13 Aprovado em: 20/08/14 